\title{
THE EFFECT OF TEMPERATURE ON THE MECHANICAL PROPERTIES AND ACTION POTENTIAL OF ISOLATED FROG VENTRICLE
}

\author{
Hidenobu Mashima And Moto Matsumura* \\ Department of Physiology, School of Medicine, \\ Juntendo University, Hongo, Tokyo
}

Since the studies of LUNDIN (1944), the fundamental mechanical properties of cardiac muscle have been fruitfully studied by many investigators (ABBOTT \& Mommaerts 1959; Mommaerts et al., 1960; Sonnenblick 1962a), aside from its functions as a pump. And recently Blinks \& КOCH-WESER (1963) and KOCH-WESER \& BLINKS (1963) reviewed the studies on the physical factors of contraction in cardiac muscle, including their own results. All these studies were carried out in the manner which has been done in skeletal muscle (HILL, 1938; Ritchie, 1954; Buchthal \& Kaiser, 1951; Jewell \& Wilkie, 1960). However, because the cardiac muscle can not be tetanized, the degree of activation could not be determined as done in skeletal muscle. We think it is possible to estimate the intensity of full active state from the contracture response in potassium solution.

Besides the active state, the shortening velocity, the rate of rise of tention and the work done during contraction have not been sufficiently analyzed in the frog cardiac muscle, although a great number of studies on the peak tension and the influence of beating frequency to it have been carried out (KOCH-WESER \& Blinks, 1963).

The present study was done with the purposes to determine the active state curve and the factors for the muscle to perform work, and to examine the effect of cooling on the mechanical properties in relation to the action potential and in comparison with those of skeletal muscle.

\section{METHODS}

Strips of about $1 \mathrm{~mm}$ in thickness and $8-12 \mathrm{~mm}$ in length were dissected in circular direction from the frog ventricle. The preparation obtained from more than $1 \mathrm{~mm}$ apart from the coronal sulcus did not beat spontaneously, so the frequency of con-

Received for publication June 23, 1964

* 真島英信, 松村幹郎 
traction was regulated by electrical stimulation. The cut ends would heal over one hour after dissection (NIEDERGERKE, 1956).

The diagram of the whole arrangement of mechanical system is shown in Fig. 1. The preparation was mounted horizontally in Ringer's solution, the bath (B) was $4 \times$ $3 \mathrm{~cm}$ and filled with $10 \mathrm{ml}$ of solution. One end of the preparation was connected to

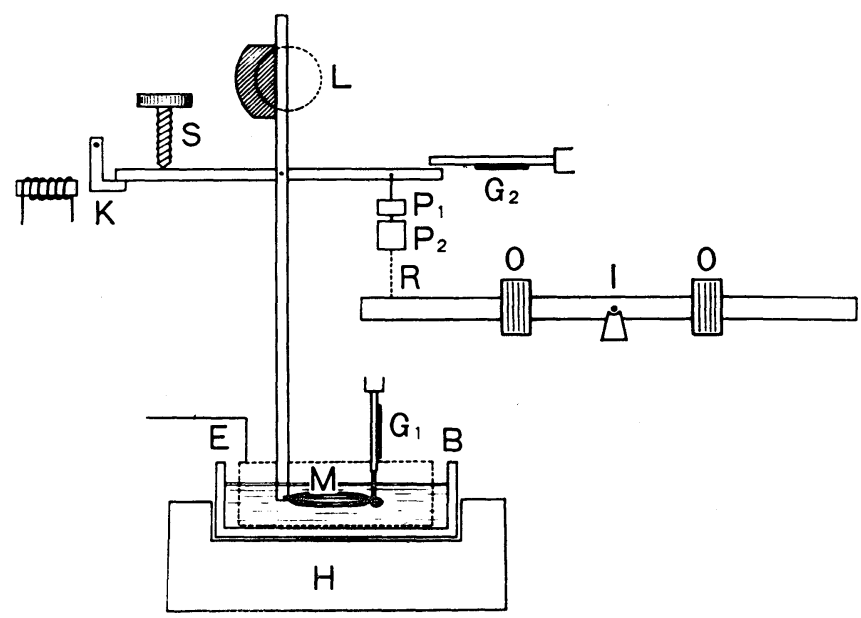

FIG. 1. The diagram of mechanical system.

$B$, bath of Ringer's solution; E, platinum foil electrode for transverse field stimulation; $\mathrm{G}_{1}, \mathrm{G}_{2}$, semiconductor strain-gauge; $\mathrm{H}$, thermoelectric temperature regulator; $\mathrm{I}$, inertia lever; $\mathrm{K}$, electromagnetic key for quick release; $\mathrm{L}$, lump for photoelectric tube; $M$, muscle; $O$, counter balance; $\mathrm{P}_{1}$, pre-load; $\mathrm{P}_{2}$, afterload; $\mathrm{R}$, thread; S, stop,

the semiconductor strain-gauge $\left(G_{1}\right)$, and the other to a cross-shaped lever made of light wood, the longest arm of which was $10 \mathrm{~cm}$ and the others were $5 \mathrm{~cm}$ each. For the isometric contraction, the lever was fixed by the electromagnetic key $(\mathrm{K})$ and the tension was recorded by strain-gauge $\left(\mathrm{G}_{1}\right)$. For the isotonic contraction the key was removed, the load $\left(\mathrm{P}_{1}+\mathrm{P}_{2}\right)$ was hung and the shortening was recorded by the photoelectric system (L). The initial length of the muscle was controlled by the pre-load $\left(\mathrm{P}_{1}\right)$ and did not change for any subsequent after-load $\left(\mathrm{P}_{2}\right)$, using the stop $(\mathrm{S})$. The inertia level (I) was connected to the isotonic lever with an inextensible thread $(R)$. Changing the inertia, the shortening velocity was controlled independently of the load or the initial length of the muscle. The moment of inertia of the lever (I) was changed by moving or exchanging the sliding balances $(O)$. After the initial acceleration phase of the contraction was over, the thread was slackened and the inertia lever had no influence on the contraction (MAshima \& TANAKA, 1954). To follow the decay of the active state, quick release method (Ritchie, 1954; Аввотt \& MoмMAERTS, 1958) was employed, using the key $(\mathrm{K})$ and strain-gauge $\left(\mathrm{G}_{2}\right)$.

The muscle was stimulated with a square pulse of $10 \mathrm{msec}$ in duration, sometimes $50 \mathrm{msec}$ was necessary at lower temperature, through platinum massive elect. rodes $(\mathrm{E})$ by the high-current stimulator (30 Watt), which was originally devised by Mostovsky \& Sandow, (1951).

Ringer's solution contained $110 \mathrm{mM}, \mathrm{NaCl} ; 2.0 \mathrm{mM}, \mathrm{KCl} ; 1.8 \mathrm{mM}, \mathrm{CaCl}_{2} ; 10 \mathrm{mM}$, $\mathrm{NaHCO}_{3} ; 10 \mathrm{mM}$ glucose, and $\mathrm{pH}$ was around 7.2. The temperature of solution was 
regulated by the thermoelectric system (MASHimA, 1963), in which the warming and cooling were effected through the bottom of the bath. Stirring the solution with bubbling air, the hunting of temperature was less than $0.2^{\circ} \mathrm{C}$ and the maximal rate of temperature change was $1^{\circ} \mathrm{C} / \mathrm{min}$ in cooling or $3^{\circ} \mathrm{C} / \mathrm{min}$ in warming.

Monophasic action potential and twitch tension were recorded simultaneously by the partition method (Mashima \& Matsumura, 1962).

\section{RESULTS}

1. Magnitude and rate of tension development. The muscle was stretched to $120 \%$ of the rest length, which is the longest length without developing any passive tension. The initial tension at $120 \%$ length was slightly decreased when the muscle was cooled. This fact means that the coefficient of expansion of resting cardiac muscle is negative. Generally, when the muscle was driven at the rate of one shock per 10 seconds (i. e. $0.1 \mathrm{c} / \mathrm{sec}$ ), the cooler was the bathing solution, the larger became the tension between $25^{\circ} \mathrm{C}$ and $8^{\circ} \mathrm{C}$. Within one minute of soaking in a certain temperature the tension reached to the steady value at that temperature. This was a great advantage for time economy in temperature experiment. When the solution was warmed back to the previous temperature, the increased tension did not decrease to the original value. But this hysteresis disappeared in the second or later series of experiment involving a cycle of cooling and warming. In Fig. 2, a

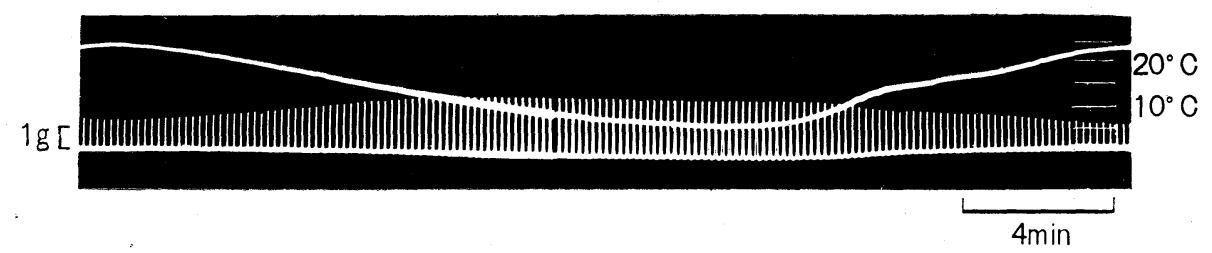

FIG. 2. The decrease in twitch tension on cooling and the increase on warming in the frog ventricle. Upper curve, temperature; lower curve, twitch tension; The muscle was stimulated at the frequency of $0.1 \mathrm{c} / \mathrm{sec}$.

case of the second series of experiment is shown. The temperature coefficients $\left(Q_{10}\right)$ of various mechanical parameters are summarized in TABLE 1 . At the driving rate of $0.1 \mathrm{c} / \mathrm{sec}$, the maximal tension, the maximal rate of rise of tension or the contraction time increased by $1.8,0.8$ or 2.3 times the control respectively for the temperature fall of $10^{\circ} \mathrm{C}$. In other words, $Q_{10}$ of them were $0.55,1.26$ and 0.43 respectively. It is clear, however, that a more vigorous response at the same temperature will show a greater maximal rate of rise "of tension, and it is necessary, in order to allow for alterations in the mere size of the response, to divide the maximal rate of rise of tension by the maximal tension. This ratio is the maximal rate of proportional rise of tension, a quantity of dimensions minus one in time and similar to the velocity constant of a chemical reaction (HARTREE \& HILL, 1921), and the temperature 
TABLE 1. Temperature coefficients $\left(Q_{10}\right)$ of mechanical parameters in frog ventricle at the driving rate of $0.1 \mathrm{c} / \mathrm{sec}$.

\begin{tabular}{r|l|c|c|c}
\hline $\begin{array}{c}\text { range of } \\
\text { temperature } \\
\text { change } \\
\left({ }^{\circ} \mathrm{C}\right)\end{array}$ & \multicolumn{4}{|c}{ temperature coefficient $\left(\mathrm{Q}_{10}\right)$} \\
\cline { 2 - 5 } & $\begin{array}{c}\text { (a) } \\
\text { maximal } \\
\text { tension }\end{array}$ & $\begin{array}{c}\text { (b) } \\
\text { max. rate of } \\
\text { rise of tension }\end{array}$ & $\begin{array}{c}\text { (c) } \\
\text { ratio } \\
(\mathrm{b}) /(\mathrm{a})\end{array}$ & $\begin{array}{c}\text { (d) } \\
\text { contraction } \\
\text { time }\end{array}$ \\
\hline $8-21$ & 0.48 & 1.20 & 2.50 & 0.44 \\
$8-22$ & 0.64 & 1.22 & 1.91 & 0.49 \\
$10-20$ & 0.60 & 1.02 & 1.70 & 0.48 \\
$8-20$ & 0.67 & 1.51 & 2.26 & 0.43 \\
$5-15$ & 0.58 & 1.29 & 2.22 & 0.45 \\
$10-20$ & 0.59 & 1.36 & 2.30 & 0.43 \\
$7-16$ & 0.59 & 1.07 & 1.80 & 0.46 \\
$5-15$ & 0.63 & 1.81 & 2.86 & 0.33 \\
$10-23$ & 0.47 & 1.06 & 2.26 & 0.43 \\
$8-25$ & 0.56 & 1.08 & 1.93 & 0.47 \\
$8-25$ & 0.54 & 1.42 & 2.62 & 0.42 \\
$10-20$ & 0.39 & 1.16 & 2.98 & 0.37 \\
$10-20$ & 0.57 & 1.51 & 2.64 & 0.44 \\
$10-20$ & 0.53 & 1.25 & 2.36 & 0.43 \\
$10-20$ & 0.48 & 1.01 & 2.10 & 0.47 \\
\hline mean & $0.55=1 / 1.82$ & 1.26 & 2.30 & $0.43=1 / 2.32$ \\
\hline
\end{tabular}

coefficient of this ratio was $1.26 / 0.55=2.30$ for $10^{\circ} \mathrm{C}$. The temperature coefficient of the maximal rate of proportional rise of tension should be equal to the reciprocal temperature coefficient of the contraction time. At any rate, it is remarkable that the tension and the duration of contraction in cardiac muscle increase so much on cooling, while the rate of tension development is nearly unchanged. Consequently, the contour of twitch curve increases almost similarly by the factor of 2.3 for the cooling of $10^{\circ} \mathrm{C}$.

Of course, the temperature coefficient depended on the driving frequency of contraction. For example, at $20^{\circ} \mathrm{C}$ the tension increased 2 or 3 times by the change in frequency from $1 \mathrm{c} / 60 \mathrm{sec}$ to $1 \mathrm{c} / 2 \mathrm{sec}$, but at $5^{\circ} \mathrm{C}$ it showed no increase for the same change. In the case of spontaneously beating preparation, the contraction increased also at low temperature, even though the frequency of beating was reduced.

2. Force-velocity curve. Under the afterload condition, the shortening velocities were measured under various loads, keeping the initial length of muscle $(L)$ constant. In FIG. 3A, the shortening velocity $(v)$ is plotted against the total load $(P)$, that is the sum of pre-load of $0.2 \mathrm{~g}$ and afterload. The intrinsic velocity, namely the ideal velocity of shortening without any external resistance, was estimated by extrapolation of the curve to the abscissa of zero load. 


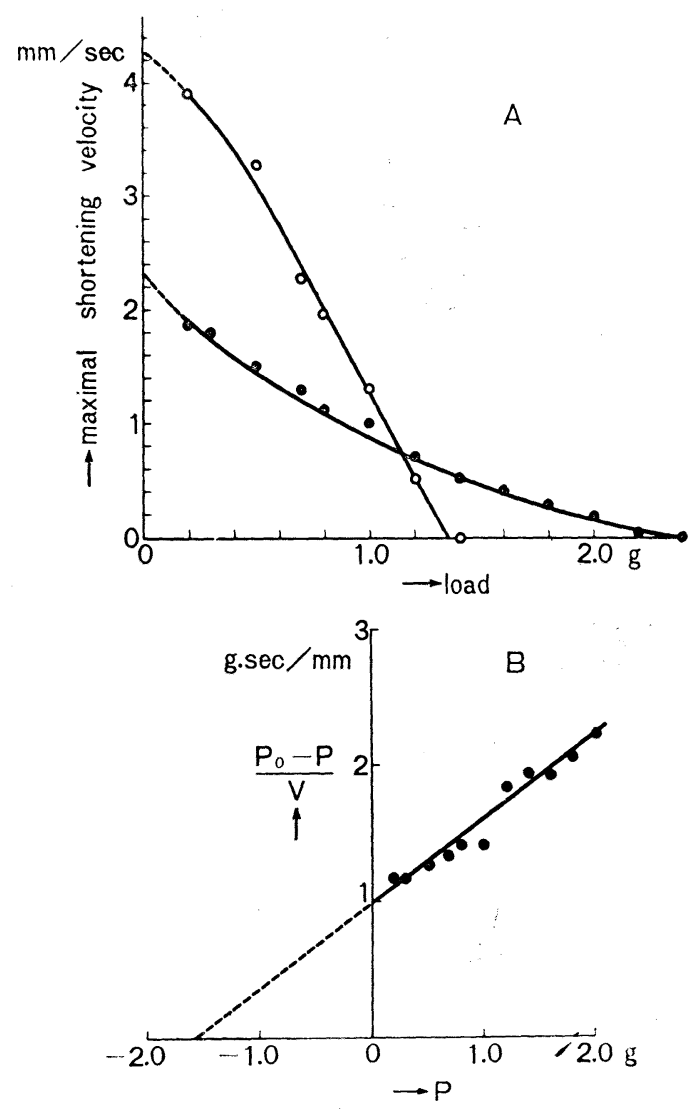

FIG. 3. A, The force-verocity relation in the frog ventricle at $23^{\circ} \mathrm{C}$ (open circle) and at $8^{\circ} \mathrm{C}$ (filled circle). B, $\left(P_{0}-P\right) / v$ was plotted against $P$ at $8^{\circ} \mathrm{C}$. Pre-load, $0.2 \mathrm{~g}$; initial length, $11 \mathrm{~mm}$; The muscle was stimulated at the frequency of $0.1 \mathrm{c} / \mathrm{sec}$.

The force-velocity curve was not hyperbolic but approximately linear at $23^{\circ} \mathrm{C}$ (FIG. 3A). But when the temperature was lower than $10^{\circ} \mathrm{C}$, the relation between $(1 / v)\left(P_{0}-P\right)$ and $P$ was quite linear (FIG. 3B), where $P_{0}$ is the maximal tension in isometric contraction. Consequently, the $P-v$ curve is hyperbolic, conforming to HILL's characteristic equation (1938),

$$
(1 / v)\left(P_{0}-P\right)=(1 / b)(P+a)
$$

From the intercept on the abscissa and the slope of the line in FIG. 3B, the dynamic constants were easily calculated ; heat constant $(a)$ is $1.7 \mathrm{~g},\left(a / P_{0}\right)$ is 0.71 , rate constant $(b)$ is $1.67 \mathrm{~mm} / \mathrm{sec}$ and $(L / b)$ is. $6.55 \mathrm{sec}$.

3. Intensity and duration of the active state. The active state curve was obtained after RITCHIE's method (1954). In FIG. 1, the inertia lever (I), loads 
$\left(\mathrm{P}_{1}, \mathrm{P}_{2}\right)$ and stop $(\mathrm{S})$ were removed, and the muscle was stretched to $120 \%$ length by the electromagnetic key $(K)$. The key was suddenly released at various instants from the stimulus during the isometric contraction by the electronic delay circuit. Then the muscle suddenly began to shorten without load until the lever collided with the tension recorder $\left(G_{2}\right)$. Afterwards the muscle again contracted isometrically at the length slightly shorter than the initial length. The amount of shortening permitted was about $10 \%$ of the initial length. Two serieses of seven records at different temperature are shown in FIG. 4. At first, the initial tension does not appear in the record, but as soon as the electromagnetic key is released, previously stretched series elastic component shortens quickly until to the length for the later isometric contraction (110\% of the rest length). Sudden rise of tension in FIG. 4 means the passive tension at the later length, and then the redevelopment of active tension is superimposed on it. If the muscle is released from $110 \%$ to $100 \%$

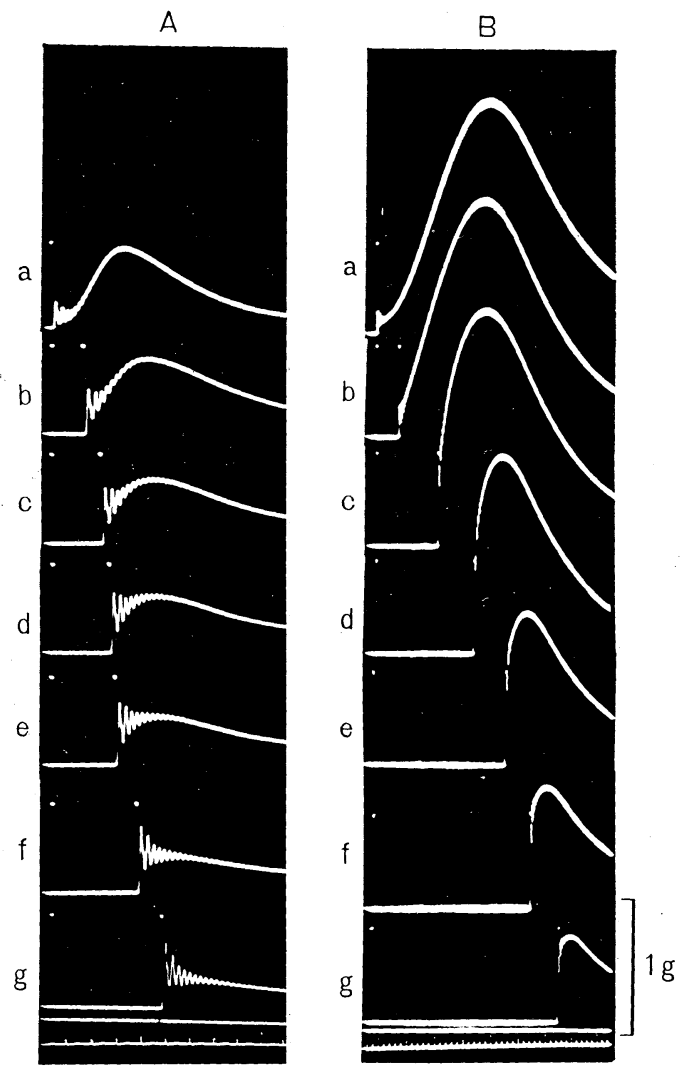

FIG. 4. Records of quick release experiment in the frog ventricle at $25^{\circ} \mathrm{C}$ (A) and at $8^{\circ} \mathrm{C}(\mathrm{B})$. Time of stimulation and of release are marked. The muscle was stimulated at the frequency of $0.1 \mathrm{c} / \mathrm{sec}$. Time scale, $0.1 \mathrm{sec}$. 
length as adopted by Ritchie (1954) or ABBotT \& MommaERTS (1958), on such sudden rise of tension level takes place. However, because the amount of active tension depended largely on the muscle length, especially near the rest length, it was considered to be better to determine the active state curve at $110 \%$ of the rest length. In this case, therefore, only the tension over the passive tension level represents the redeveloped tension. Thus, the whole course of the active state was obtained as shown in Fig. 5. Full extent of the active state in FIG. 5 was estimated by the maximal tension of potassium

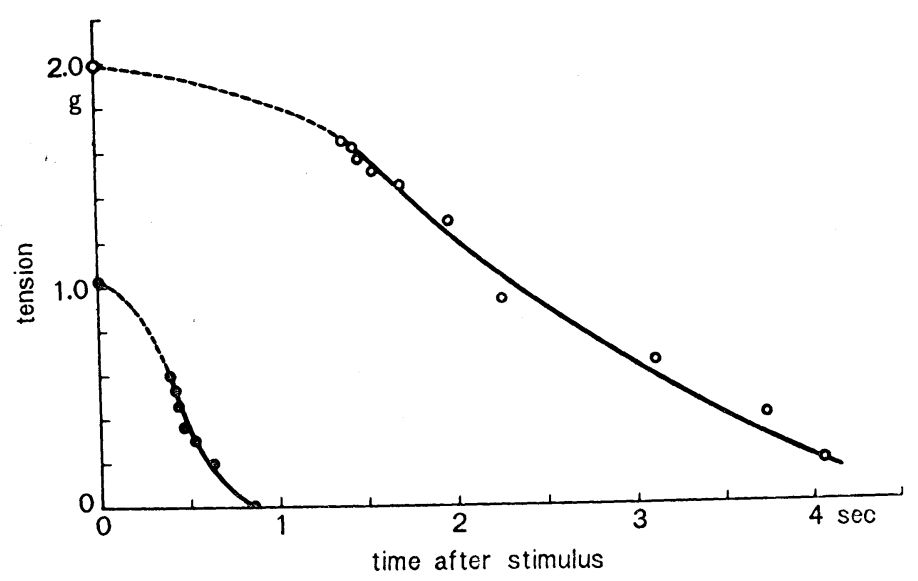

FIG. 5. The active state curve in the frog ventricle at $25^{\circ} \mathrm{C}$ (open circle) and at $8^{\circ} \mathrm{C}$ (filled circle). The muscle was stimulated at the frequency of $0.1 \mathrm{c} / \mathrm{sec}$.

contracture, instead of tetanic contraction in skeletal muscle. The composition of potassium solution was $\mathrm{KCl}, 62 \mathrm{mM}$; sucrose, $111 \mathrm{mM} ; \mathrm{CaCl}_{2}, 10 \mathrm{mM}$ and $\mathrm{NaHCO}_{3}, 10 \mathrm{mM}$, which can produce the maximal and sustained contracture (LÜTTGAU \& NiEDERGERKE, 1958). At low temperature, the contracture tension as well as the ratio of twitch tension to contracture tension was increased, and as for the active state curve, (i) the duration was prolonged, (ii) the rate of decay was slowed and (iii) the intensity was increased. $Q_{10}$ of the duration of the active state is roughly $1 / 2.6$ and that of the intensity was $1 / 1.5$.

During the sustained potassium contracture, the muscle could develop further tension by strong alternating current $(50 \mathrm{c} / \mathrm{sec}$.) stimulation for $1 \mathrm{sec}$, the amount of which was about $10 \%$ of the contracture tension at room temperature. Similar contraction has been found by CSAPO \& KURIYAMA (1962) in the rat uterine muscle. Therefore, the full intensity of active state may be about $10 \%$ stronger than estimated from the maximal contracture tension.

4. Work done by muscle. Work $(W)$ done during isotonic contraction, lifting the load $(P)$, is written,

$$
W=P x
$$



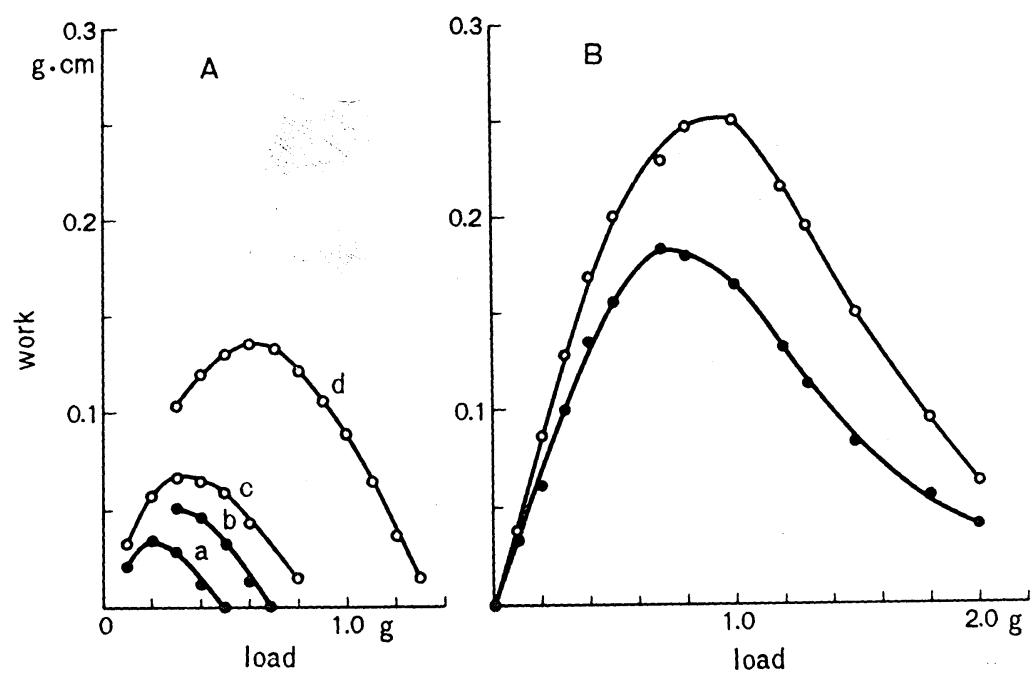

FIG. 6. The relation between the work and the load in the frog ventricle at $10^{\circ} \mathrm{C}$ (open circle) and at $20^{\circ} \mathrm{C}$ (filled circle). The initial length did not change in A (afterload method) and changed in B. In a and c, pre-load was $0.1 \mathrm{~g}$, in b and $\mathrm{d}$, pre-load was $0.3 \mathrm{~g}$. The muscle was stimulated at the frequency of $0.1 \mathrm{c} / \mathrm{sec}$.

Where, $x$ is the amount of shortening. FIG. 6A represents the relationship between the work and the load when the inital length is kept constant by the afterload method, and FIG. $6 \mathrm{~B}$ shows the same relationship when the initial length was permitted to change by the load. From these figures it is obvious that there are three factors for the muscle to perform the work, namely the initial length of the muscle, the load and the temperature. The optimal load, under which the muscle could perform the maximal work, was increased at longer initial length and at lower temperature.

If the inertia lever (FIG. 1, I) is connected to the isotonic lever, the muscle has to shorten against the inertial resistance. In this case, the work is represented as follows (MASHIMA \& TANAKA, 1954),

$$
W=P x+\frac{1}{2} M v_{m}^{2}
$$

Where, $M$ is the equivalent mass of the inertia lever and $v_{m}$ is the maximal velocity of shortening. The tension and shortening during the contraction against inertia were recorded simultaneously. When the equivalent mass of the lever increased, far greater tension than the load was developed in the accelerated phase of contraction, and both the amount of shortening and the maximal velocity decreased, while the time to peak tension was prolonged, as shown in Fig. 7 from $A$ to $E$ at $24^{\circ} \mathrm{C}$ or from $F$ to $J$ at $10^{\circ} \mathrm{C}$.

The relation between the maximal velocity and the equivalent mass was expressed by a following experimental equation, 


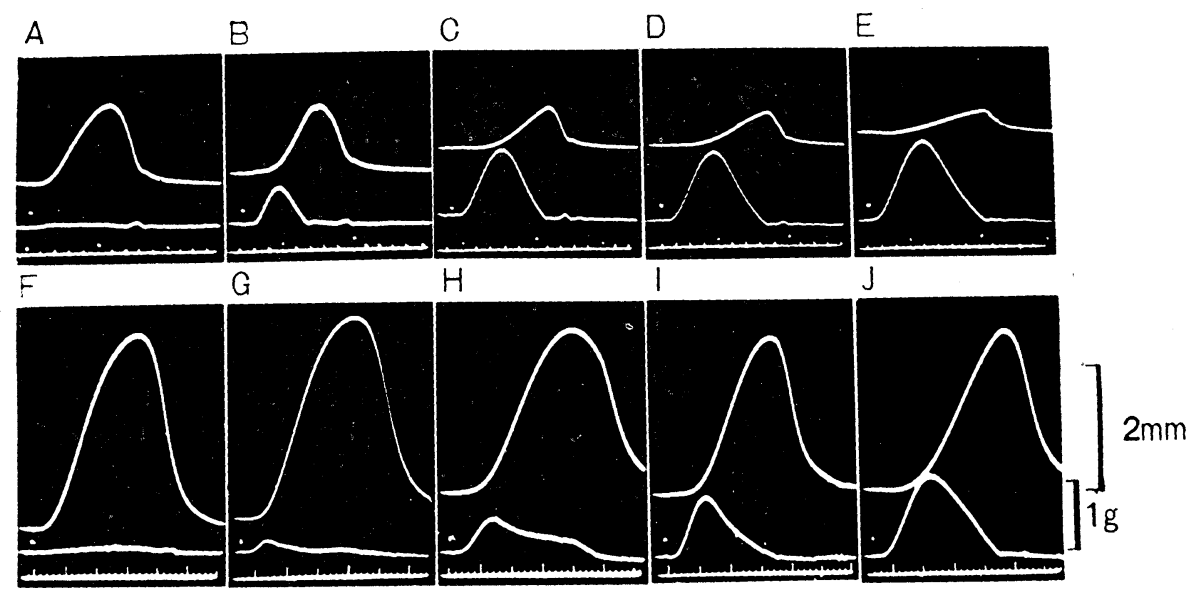

FIG. 7. Simultaneous records of the tension (upper curve) and the shortening (lower curve) during the contraction with inertia lever in the frog ventricle at $24^{\circ} \mathrm{C}(\mathrm{A}-\mathrm{E})$ and at $10^{\circ} \mathrm{C}(\mathrm{F}-\mathrm{J})$. Equivalent mass of the inertia lever was $0 \mathrm{~g}$ in $A$ and $F, 40 \mathrm{~g}$ in $B$ and $G, 260 \mathrm{~g}$ in $C$ and $H, 360 \mathrm{~g}$ in $D$ and $I, 1060 \mathrm{~g}$ in $E$ and J. Load was $0.2 \mathrm{~g}$. The muscle was stimulated at the frequency of $0.1 \mathrm{c} / \mathrm{sec}$. Time scale, $0.1 \mathrm{sec}$.

$$
v_{m}=A M^{-1 / k}
$$

Where, $A$ and $k$ are constants. According to MASHima \& TANAKA, (1954), $k$ is approximately 3 in frog sartorius muscle, but in frog ventricle, $3 \sim 6$ was obtained. In the case of passive shortening of a simple viscoelastic model, $k=2$ would be expected. Therefore, there should be some energy liberating mechanism to overcome the external resistance in skeletal muscle, and this mechanism should be more effective in cardiac muscle.

Measuring $x$ and $v_{m}$, the work was calculated. Or the shortening was recorded by the vertical axis and the tension by the horizontal axis of the cathode ray oscilloscope, then the work was directly measured from the area inside of the LissAJOU's figure during a twitch. The relation between the work and the equivalent mass is shown in FIG. 8. Curve $I$ is the work or the increase in potential energy $(P x)$, curve II is the kinetic energy given to the inertia lever $\left(M v_{m}^{2} / 2\right)$ and curve III is the sum of them $(W)$. The total work done by muscle, especially the kinetic energy, increased with the increase in equivalent mass. It may be said that the muscle can mobilize the more mechanical energy by slowing of the shortening velocity, even if the resistance to shortening increased.

At low temperature the amount of shortening, the maximal velocity and the time to peak tension were affected little by the change in equivalent mass (FIG. 8, IV, V, VI), probably because the intrinsic velocity is sufficiently slow. 


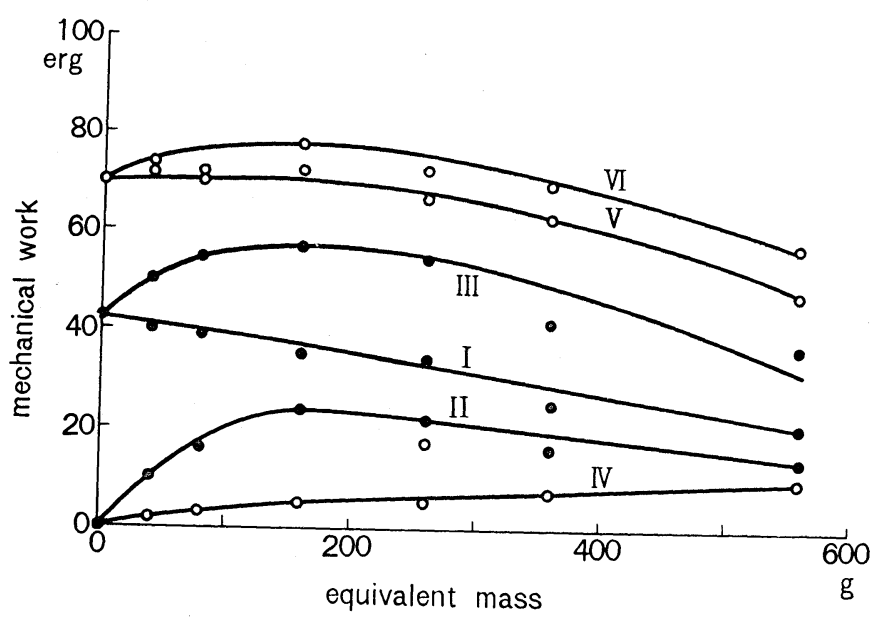

FIG. 8. The relation between the mechanical work and the equivalent mass in the frog ventricle at $24^{\circ} \mathrm{C}$ (I, II, III) and at $10^{\circ} \mathrm{C}$ (IV, V, VI). I or IV is the work done for lifting the load, and II or $\mathrm{V}$ is the kinetic energy given to the inertia lever. $I I I=I+I I, V I=I V+V$. The muscle was stimulated at the frequency of $0.1 \mathrm{c} / \mathrm{sec}$.

5. Duration of action potential and contraction time. The monophasic action potential was recorded by the partition method simultaneously with the tension curve at various temperatures (FIG. 9). At lower temperatures, the contraction time as well as the duration of action potential was prolonged. On the other hand, the spike height was slightly decreased. Therefore, as far as the coupling relation between the spike height and the peak tension is concerned, the efficiency of coupling decreased at higher temperature, as pointed out by MASHima et al. (1962) in frog sartorius muscle. At the temperature lower than $5^{\circ} \mathrm{C}$, the cardiac muscle lost the all-or none property, the spike height and tension increased with the strength of stimulus.

In FIG. 9A, the time of maximum in tension corresponds to the end of the falling phase of action potential, but in FIG. 9D, it does to the beginning of
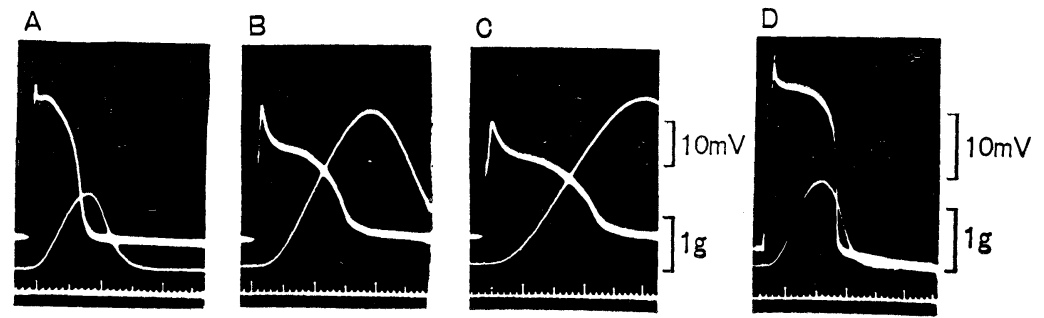

FIG. 9. Simultaneous records of the tension (lower curve) and the action potential (upper curve) by the partition method in the frog ventricle. A, $20^{\circ} \mathrm{C} ; \mathrm{B}$, $10^{\circ} \mathrm{C} ; \mathrm{C}, 5^{\circ} \mathrm{C} ; \mathrm{D}$, another preparation at $15^{\circ} \mathrm{C}$. The muscle was stimulated at the frequency of $0.1 \mathrm{c} / \mathrm{sec}$. Time scale, $0.1 \mathrm{sec}$. 
repolarization. In all examples, however, the time when the tension reached its peak shifted on cooling to the later phase of the action potential.

In order to determine the duration of action potential with much accuracy, the duration was measured at the level of half of the spike height. The temperature dependence of the contraction time and the duration of action potential are shown in FIG. 10 . Between $5^{\circ} \mathrm{C}$ and $15^{\circ} \mathrm{C}$, temperature coefficient $\left(\mathrm{Q}_{10}\right)$ of the contraction time is about $1 / 2.3$ for $10^{\circ} \mathrm{C}$ and that of the duration of action potential is $1 / 1.52$. Taking account of the fact that the mechanical threshold became higher at low temperature, the difference of temperature coefficient between electrical and mechanical events would be more prominent at lower temperature.

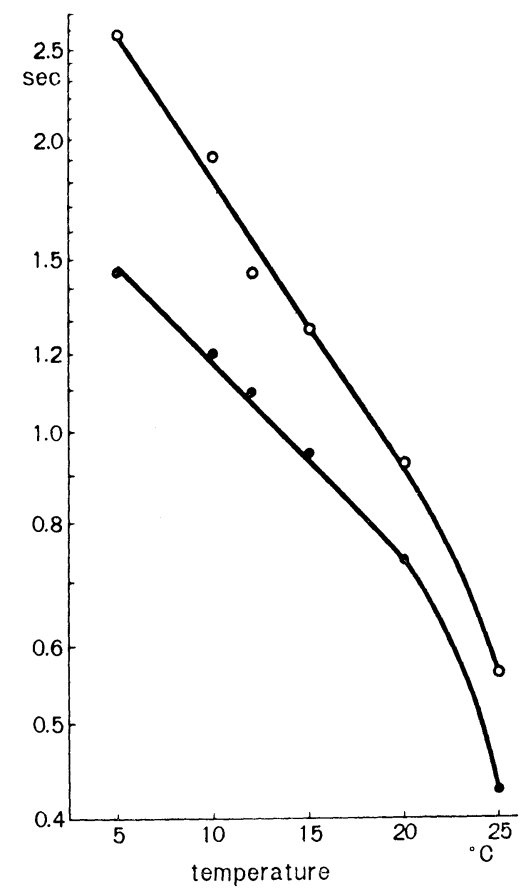

FIG. 10. The effect of temperature on the contraction time (open circle) and the duration of action potential (filled circle) in the frog ventricle. The muscle was stimulated at the frequency of $0.1 \mathrm{c} / \mathrm{sec}$.

\section{DISCUSSION}

The temperature coefficient of the maximal rate of proportional rise of tension was almost equal to the reciprocal temperature coefficient of the contraction time in frog ventricle. This fact means that the rate of chemical process in contraction of cardiac muscle is slowed with temperature fall of 
$10^{\circ} \mathrm{C}$ by the coefficient of 2.3 but at the same time the duration of it is prolonged by the same coefficient. On the other hand, the following relation is also introduced;

$$
\begin{array}{r}
\left(Q_{10} \text { of tension }\right)=\left(Q_{10} \text { of rate of rise of tension }\right) \\
\times\left(Q_{10} \text { of contraction time }\right)
\end{array}
$$

Many investigations about the effect of change in temperature on the rate and magnitude of tension in skeletal muscle were reviewed by WALKER (1960). We also measured the $Q_{10}$ of twitch tension in frog sartorius muscle and obtained 0.85 between $15^{\circ} \mathrm{C}$ and $25^{\circ} \mathrm{C}$ (MAshima et al., 1962). Hill (1951) observed a decrease in twitch tension of sartorius muscle to about a half on cooling from $21.9^{\circ} \mathrm{C}$ to $0^{\circ} \mathrm{C}$. Anyway, in comparison of cardiac muscle with skeletal muscle, it is obvious that the reciprocal temperature coefficient of tension in cardiac muscle $(1 / 0.55=1.82)$ is far greater than that in skeletal muscle (for example, $1 / 0.85=1.17$ ). Furthermore, in our measurement, $\mathrm{Q}_{10}$ of the maximal rate of rise of tension was 2.0 , and that of contraction time was $1 / 2.22$ between $10^{\circ} \mathrm{C}$ and $20^{\circ} \mathrm{C}$ in frog sartorius muscle. The temperature coefficient of the maximal rate of proportional rise of tension in skeletal muscle is 2.35 (or 2.0/ 0.85), this figure well coincides with that of cardiac muscle. Also this is quite comparable with the figure in frog sartorius muscle reported by HARTREE \& HILL (1921), that was 2.40 for $10^{\circ} \mathrm{C}$. In skeletal muscle, when the temperature decreases, the rate of tension development decreases and the contraction time increases, and as a whole the magnitude of twitch tension does not show much change. In cardiac muscle, however, the rate of tension development does not decrease so much as in skeletal muscle on the same temperature fall, that is the reason why the contraction tension of cardiac muscle increases far more than that of skeletal muscle at lower temperatures. As the cause of such a less decrease in the rate of tension development on cooling in cardiac muscle, it is reasonable to assume the potentiation of the degree of the active state at low temperature.

It should be reminded that the contraction of cardiac muscle depends largely on the driving frequency. On the inotropic action, АвBOTT \& MOMMAerts (1958), BRAdy, AbBotT \& MommaerTs (1960), SONNENBlick (1962a) and KOCH-WESER \& BLINKS (1963) have investigated in detail. SonNENBLICK pointed out that the rate and magnitude of tension development were altered in quite different ways by the change in frequency of contraction. In our experiments at $5^{\circ} \mathrm{C}$, the maximal tension and the rate of tension development did not depend on the beating frequency. The maximal frequency where each contraction was completely separated was $0.2 \mathrm{c} / \mathrm{sec}$ at $5^{\circ} \mathrm{C}$, so it was difficult to examine the effect of higher driving frequency on the temperature coefficients of mechanical parameters.

Force-velocity relations in cat papillary muscle (SonNEnBLICK, (1962a, b) 
and in some smooth muscles (ABBotT \& Lowy 1958, CsAPO \& GoodAll, 1954,) were hyperbolic, conforming to HILL's equation (1938). In frog ventricle the $P-v$ relation was hyperbolic at $8^{\circ} \mathrm{C}$ but rather linear at $23^{\circ} \mathrm{C}$. Probably the viscosity of sarcoplasm is so high even at higher temperature that the maximal velocity of shortening under light load is limited by certain degree. The dynamic constant $\left(a / P_{0}\right)$ was 0.71 in frog ventricle and nearly equal to the figure in cat papillary muscle (SONNENBLICK, 1962a), but the rate constant $(L / b)$ was 6.55 in frog ventricle and 1.5-2.5 in cat papillary muscle. Granting the difference in temperature, and estimating $\mathrm{Q}_{10}$ of $b$ was 2.05 (HILL, 1938), the rate of energy release in frog heart may be fairly equal to that in mammalian heart muscle. The value of $L / b$ is 1.82 in frog sartorius muscle (HILL, 1938), 3.00 in frog semitendinous muscle (BUCHTHAL \& KAISER 1951), and 13.7 at $37.5^{\circ} \mathrm{C}, 19.0$ at $27.5^{\circ} \mathrm{C}$ in rabbit uterine muscle (CsAPo \& Goodall, 1954). There must be some difference in the rate of energy release between cardiac muscle and skeletal or smooth muscle, but it is necessary to consider that $b$ is changed by the change in contractility (SoNNENBLICK, (1962a).

WINEGRAD \& SHANES (1962) reported that there was a close relation between the strength of contraction and calcium influx. Recently, NiEderGerke (1963a, b) measured the movement of ${ }^{45} \mathrm{Ca}$ in frog ventricle and discussed the relation between twitch tension and concentration of activator calcium which was released at the inner surface of membrane during action potential. $\mathrm{He}$ assumed three reactions; (i) the entry of activator $\mathrm{Ca}$, (ii) the deactivation of $\mathrm{Ca}$ and (iii) the outflow of $\mathrm{Ca}$ and the rate constants of them were $\alpha, \beta$ and $\gamma$ respectively. It was suggested that the twitch tension depends upon the level of activator $\mathrm{Ca}$, which is the difference between the entry and the deactivation of activator $\mathrm{Ca}$. Assuming that the rate constant $\alpha$ does not decrease so much, but $\beta$ shows much decrease on cooling, it is plausible that not only the duration of $\mathrm{Ca}$-influx will be prolonged in regard to the prolonged action potential but also the amount of activator $\mathrm{Ca}$ will be increased by the slow deactivation, even though the absolute value of $\alpha$ is reduced at low temperature. It is interesting to compare this fact with the time course of active state curve (FIG. 5). If the tension depends upon the level of activator $\mathrm{Ca}$ or $\mathrm{Ca}$-influx, the active state curve should exactly reflex the Ca-influx curve. As to the degree of activation in cardiac muscle, NiEdERGERKE (1956) suggested the increase of it when raised the external calcium concentration. AbBotT \& Mommaerts (1958) and Trendelenburg \& Lúllmann (1958) recorded the decay curve of the active state and measured the duration of it in cat papillary muscle and in frog ventricle, but did not show the whole course of it or the intensity of active state. BLINKS \& KOCH-WESER (1963) reviewed investigations on the influence of temperature on the active state and stated that many workers showed the prolongation of the active state at low temperature but unfortunately the change in time course of contraction or in the 
degree of activation had not been sufficiently elucidated. The active state curve apparently shows the increase in duration and in degree, too, at low temperature (FIG. 5). But we could not determine whether the steady plateau phase of the active state surely exists or not. As WEBER et al. (1963) suggested about the relation between the active state and $\mathrm{Ca}$-actomyosin complex, the accumulated activator calcium may intensify the active state at low temperature. TRENDRENBURG \& LÚLLMANN (1958) concluded that the stretching caused an increase in tension in the contractile system of the cardiac muscle, bacause the duration of the active state was unchanged. But it is likely that the degree of activation is increased by the stretching.

The temperature coefficient $\left(\mathrm{Q}_{10}\right)$ of the duration of action potential was $1 / 1.52$, but that of active state or contraction time was $1 / 2.3$. From this fact it is suggested that the prolongation of action potential may result in a prolongation of $\mathrm{Ca}$-influx or the active state but some coupling process, probably of chemical nature with $\mathrm{Q}_{10}$ of about 2 , should exist between them, this process is the excitation-contraction coupling in real meaning. TRAUTWEN \& DUDEL (1954) described that the duration of contraction in cat papillary muscle depended on the duration of action potential, and BLEICHERT \& REICHEL (1962) suggested that the active state inhibited by sudden release could redevelop as far as the depolarization continued. However, many investigators (NIEDERGERKE, 1956; Kotowski et al., 1959; ANTONi et al., 1960; ENGSTFELD et al., 1961; Weidmann, 1959; Schmidt \& Chang, 1961) have pointed out that the duration of action potential did not control the duration of contraction. It is rather natural that the change in temperature affects the electrical events on membrane in a different way from the chemical or mechanical processes in the excitation-contraction coupling.

According to SonNENBLICK (1962a, 1963), the work performed depended upon the pre- and afterload in the afterload contraction. From the present results, the velocity of shortening besides the temperature must be taken into consideration. Under pure isotonic condition the shortening velocity depends only on the load, which is controlled by $P-v$ relation, but where the inertia force exists, the muscle can mobilize more energy and perform more work in cardiac muscle, much more effectively than MASHIMA \& TANAKA (1954) and MASHima \& MATSUmura (1960) pointed out in skeletal muscle. The amount of shortening would be determined not only by the time factor from the stimulus, but also by the geometrical factor in relation to the increase in length of overlapping of myofilaments. Without this energy mobilizing mechanism the cardiac muscle can not expel the sufficient blood against the high arterial pressure. 


\section{SUMMARY}

1. The effect of temperature on the mechanical properties and the action potential of isolated frog ventricle were studied.

2. On cooling to between $25^{\circ} \mathrm{C}$ and $8^{\circ} \mathrm{C}$, the maximal tension and the contraction time increased while the maximal rate of rise of tension decreased, and the values of $Q_{10}$ were $1 / 1.82,1 / 2.32$ and 1.26 respectively. The maximal rate of proportional rise of tension, i. e. the ratio of the maximal rate of rise of tension devided by the maximal tension, decreased on cooling, and $\mathrm{Q}_{10}$ of it was equal to the reciprocal $\mathrm{Q}_{10}$ of the contraction time.

3. The force-velocity curve was hyperbolic at $8^{\circ} \mathrm{C}$, but rather linear at $23^{\circ} \mathrm{C}$. 4. Not only the duration but also the intensity of the active state increased on cooling, and $\mathrm{Q}_{10}$ of them were about $1 / 2.6$ and $1 / 1.5$ respectively.

5. The work performed depended on the initial length of the muscle, the load and the temperature. Under the condition that the muscle was encounted by inertia force, however, more work than expected from above three factors was performed, accompanying the slowing of contraction.

6. $\mathrm{Q}_{10}$ of the duration of action potential was $1 / 1.52$, this is quite different from $Q_{10}$ of the contraction time or the duration of the active state.

7. The relation between the active state and calcium movement, and the energy mobilizing mechanism in cardiac muscle were discussed.

\section{REFERENCES}

1) Aвbott, B. C. And Mommaerts, W.F.H. M. (1958) A study of inotropic mechanisms in the papillary muscle preparation. J. gen. Physiol. 42: 533-551.

2) Аввотт, B.C. And Lowy, J. (1958) Contraction of molluscan smooth muscle. J. Physiol. 141: 385-397.

3) Antoni, H., Engstfeld, G. And Fleckenstein, A. (1960) Inotrope Effekte von ATP und Adrenalin am hypodynamen Froschmyokard nach electromechanischer Entkoppelung durch Ca++-Entzug. Pfiig. Arch. ges. Physiol. 272: 91-106.

4) Bleichert, A. And Reichel, H. (1962) Die Hemmung der Erschlaffung beim Herzmuskel des Kalt-und Warmblüters. Pflïg. Arch. ges. Physiol. 276: 242-249.

5) Blinks, J.R. And Koch-Weser, J. (1963). Physical factors in the analysis of the actions of drugs on myocarial contractility. Pharmacol. Rev. 15: 531-599.

6) Brady, A. J. Abbott, B. C. And Mommaerts, W.F.H. M. (1960) Intropic effects of trains of impulses applied during the contraction of cardiac muscle. J. gen. Physiol. $44:$ 414-432.

7) Buchtal, F. And Kaiser, E. (1951) The rheology of the cross striated muscle fibre. Dan. Biol. Med. $21: 1-318$.

8) Csapo, A. And Goodall, M. (1954) Excitability, length tension relation and kinetics of uterine muscle contraction in relation to hormonal status. J. Physiol. $126: 384-395$.

9) Csapo, I. A. And Kuriyama, H.A. (1963) Effects of ions and drugs on cell membrane activity and tension in the postpartum rat myometrium. J. Physiol. 165 : 575-592. 
10) Engstfeld, G., Antoni, H. And Fleckenstein, A. (1961) Die Restitution der Erregungsfortleitung und Kontraktionskraft des $K^{+}$-gelähmten Frosch-und Säugetiermyokards durch Adrenalin. Pflïg. Arch. ges. Physiol. 273 : 145-163.

11) Hartree, W. And Hill, A. V. (1921) The nature of the isometric twitch. $J$. Physiol. 55 : 389-411.

12) Hill, A.V. (1938) The heat of shortening and the dynamic constants of muscle. Proc. Roy. Soc. B126: 136-195.

13) Hill, A.V. (1951) The influence of temperature on the tension developed in an isometric twitch. Proc. Roy. Soc. B138: 349-354.

14) Jewell, B.R. And Wilkie, D.R. (1958) An analysis of the mechanical components in frog's striated muscle. J. Physiol. $143: 515-543$.

15) Kotowski, H., Antoni, H. And Fleckenstein, A. (1959) Elektrophysiologische Studien zur Aufhebung der Kaliumlähmung des Froschmyokards durch ATP. Pfiug. Arch. ges. Physiol. 270: 85-102.

16) Koch-Weser, J. And Blinks, J.R. (1963) The influence of the interval between beats on myocardial contractility. Pharmacol. Rev. 15: 601-652.

17) Lundin, G. (1944) Mechanical properties of cardiac muscle. Acta. physiol. scand. 7: 1-96.

18) Lüttgau, H.C. And Niedergerke, R. (1958) The antagonism between Ca and $\mathrm{Na}$ ions on the frog's heart. J. Physiol. 143: 486-505.

19) Mashima, H. And Tanaka, N. (1954) Studies on the tension and shortening as well as the work done during muscle twitch and tetanus. Jap. J. Physiol. 4 : 290-305.

20) Mashima, H. And Matsumura, M. (1960) On the relation between force and shortening during muscle twitch. Jap. J. Physiol. 10: 602-609.

21) Mashima, H., Matsumura, M. And Nakayama, Y. (1962) On the coupling relation between action potential and mechanical response during repetitive stimulation in frog sartorius muscle. Jap. J. Physiol. 12:324-336.

22) Mashima, H. And Matsumura, M. (1962) Roles of external ions in the excitationcontraction coupling of frog skeletal muscle. Jap. J. Physiol. 12:639-653.

23) Mashima, H. (1963) A small thermostatic bath controlled by thermoelectric system. Juntendo Med. J. 8: 94-98. (in Japanese)

24) Mommaerts, W.F.H.M., Abbott, B.C. And Whalen, W.J. (1960) Selected topics on the physiology of the heart. Structure and function of muscle (ed. Bourne, G. H.) II : 517-556. Acad Press. New York.

25) Mostovsky, D. And Sandow, A. (1951) High output, dual pulse, electronic stimulator for physiologic purposes. Eledtronics. 24: 114-117.

26) Niedergerke, R. (1956) The "staircase" phenomenon and the action of calcium on the heart. J. Physiol. 134: 569-583.

27) Niedergerke, R. (1963a) Movements of Ca in frog heart ventricles at rest and during contractures. J. Physiol. $167: 515-550$.

28) Niedergerke, R. (1963b) Movements of Ca in beating ventricles of the frog heart. J. Physiol. $167: 551-580$.

29) Ritchie, J.M. (1954) The effect of nitrate on the active state of muscle. $J$. Physiol. 126 : 155-168.

30) Schmidt, R.F. And Chang, J.J. (1961) Aktionspotential und Mechanogramm von Purkinje-Fäden in tiefer Temperature. Pflüg. Arch. ges. Physiol. 272: 393-399.

31) Sonnenblick, E.H. (1962a) Implications of muscle mechanics in the heart. Fed. Proc. 21 : 975-990.

32) Sonnenblick, E.H. (1962b) Force-velocity relations in mammalian heart muscle. Amer. J. Physiol. 202 : 931-939. 
33) Sonnenblick, E.H. And Dowing, S.E. (1963) Afterload as a primary determinant of ventricular performance. Amer. J. Physiol.

34) Trautwein, W. And Dudel, J. (1954) Aktionspotential und Mechanogramm des Katzenpapillarmuskels als Funktions der Temperature. Pflïg. Arch. ges. Physiol. $266: 104-115$.

35) Trendelenburg, U. and Lüllmann, H. (1958) Über die Messung des 'active state' am Herzmuskel des Frosches. Biochim. biophys. Acta. 29: 13-20.

36) WALkER, S.M. (1960) The relation of stretch and of temperature to contraction of skeletal muscle. Part II. Amer. J. Physic. Med. 39: 234-258.

37) Weber, A., Herz, R. And Resiss, I. (1963) On the mechanism of the relaxing effect of fragmented sarcoplasmic reticulum. J. gen. Physiol. 46, 679-702.

38) WeIDMANN, S. (1959) Effect of increasing the calcium concentration during a single heart-beat. Experientia. 15: 128-130.

39) Winegrad, S. And Shanes, A. M. (1962) Calcium flux and contractility in guinea pig atria. J. gen. Physiol. $45:$ 371-394. 